\title{
INDÚSTRIA CULTURAL E SEMIFORMAÇÃO: DEMOCRACIA E EDUCAÇÃO SOB ATAQUE NOS PAÍSES IBERO-AMERICANOS À LUZ DA TEORIA CRÍTICA
}

\author{
INDUSTRIA CULTURAL Y SEMI-FORMATION: DEMOCRACY Y EDUCATION BAJO \\ ATAQUE EN PAíSES IBEROAMERICANOS EN LUZ DE LA TEORIA CRITICA
}

\author{
CULTURAL INDUSTRY AND SEMI-FORMATION: DEMOCRACY AND EDUCATION \\ UNDER ATTACK IN IBERO-AMERICAN COUNTRIES IN LIGHT OF CRITICAL THEORY
}

\author{
Marta Regina Furlan de OLIVEIRA ${ }^{1}$ \\ Maria Terezinha Bellanda GALUCH ${ }^{2}$ \\ Carlos Antônio GIOVINAZZO JÚNIOR ${ }^{3}$
}

RESUMO: Este ensaio objetiva refletir, urdidos pelos fundamentos da Teoria Crítica da Sociedade, sobre indústria cultural e semiformação (Halbbildung) no contexto dos países ibero-americanos. $\mathrm{O}$ conceito de indústria cultural não só permanece atual como é fundamental para compreender a semiformação ou a formação danificada. A reflexão está ancorada em M. Horkheimer, T. W. Adorno e H. Marcuse, pensadores da primeira geração da Escola de Frankfurt. A formação (Bildung), conforme assumida por esses autores, pode oferecer os substratos necessários para a práxis de resistência ao processo que impede o florescimento de individualidade autônoma, no qual a democracia tem sido atacada.

PALAVRAS-CHAVE: Educação. Indústria Cultural. Semiformação. Teoria Crítica da Sociedade.

RESUMEN: Este ensayo pretende reflexionar, guiado por los fundamentos de la Teoría Crítica de la Sociedad, sobre la industria cultural y la semiformación (Halbbildung) en el contexto de los países iberoamericanos. El concepto de la industria cultural no sólo sigue siendo actual, sino que es fundamental para entender la semiformación o la formación deteriorada. La reflexión está anclada en M. Horkheimer, T. W. Adorno y H. Marcuse, pensadores de la primera generación de la Escuela de Frankfurt. La formación (Bildung), tal y como asumen estos autores, puede ofrecer los sustratos necesarios para la praxis de resistencia al proceso que impide la floración de la individualidad autónoma, en la que la democracia ha sido atacada.

PALABRAS CLAVE: Educación. Industria Cultural. Semiformación. Teoría Crítica de la sociedad.

${ }^{1}$ Universidade Estadual de Londrina (UEL), Londrina - PR - Brasil. Docente do programa de pós-graduação em Educação. Doutora em Educação. ORCID: http://orcid.org/0000-0003-2146-2557. Lattes: http://lattes.cnpq.br/ 8423465824507075. E-mail: marta.furlan@yahoo.com.br

${ }^{2}$ Universidade Estadual de Maringá (UEM), Maringá - PR - Brasil. Professora do Departamento de Teoria e Prática da Educação. ORCID: https://orcid.org/0000-0001-5154-9819. Lattes: http://lattes.cnpq.br/4862416685441579. E-mail: mtbgaluch@uem.br

${ }^{3}$ Pontifica Universidade Católica de São Paulo (PUC), São Paulo - SP - Brasil. Docente do Programa de Estudos PósGraduados em Educação: História, Política, Sociedade. ORCID: https://orcid.org/0000-0001-9314-4406. Lattes: http://lattes.cnpq.br/5969230919823134. E-mail: cgiobinazzo@pucsp.br 
ABSTRACT: This essay aims to reflect, guided by the foundations of the Society's Critical Theory, on cultural industry and semiformation (Halbbildung) in the context of Ibero-American countries. The concept of the cultural industry not only remains current but is fundamental to understand semi-formation or impaired formation. The reflection is anchored in M. Horkheimer, T. W. Adorno and H. Marcuse, thinkers of the first generation of the Frankfurt School. The formation (Bildung), as assumed by these authors, can offer the necessary substrates for the praxis of resistance to the process that prevents the flowering of autonomous individuality, in which democracy has been attacked.

KEYWORDS: Education. Cultural Industry. Semiformation. Critical Theory of society.

\section{Introdução}

O que nos propuséramos era, de fato, nada menos do que descobrir por que a humanidade, em vez de entrar em um estado verdadeiramente humano, está se afundando em uma nova espécie de barbárie (ADORNO; HORKHEIMER, 1985, p. 11).

O que é essencial do conceito de indústria cultural tanto permanece atual como é relevante para a compreensão da semiformação ou da formação danificada - forma de socialização predominante. O preço pago pelas grandes mudanças no mundo social, econômico e cultural tem sido a ruína progressiva da formação cultural e da própria vida. No estágio presente do capitalismo avançado essa situação não deixa qualquer nação ilesa, quer dizer, atinge todas as populações, portanto também as dos países ibero-americanos que, igualmente, sofrem a repressão exercida pela indústria cultural, cuja aparência é a da democratização de acesso aos bens culturais e, por isso, a de que a ciência e a tecnologia são neutras e atuam para que todos possam desfrutar dos seus resultados em prol de uma vida digna.

Sua infatigável expansão com a postura aparentemente democrática e liberal realiza impiedosamente os ditames de um sistema de dominação econômica e cultural sobre a vida dos indivíduos e, desse modo, legitima sua existência pela irracionalidade com que o esclarecimento atua em favor da reprodução do sempre idêntico.

Este ensaio busca ampliar o horizonte da reflexão acerca da indústria cultural e da formação danificada, em um contexto cuja indústria cultural adquiriu grau elevado de sofisticação e de penetração, inclusive, nos recônditos espaços do Brasil e dos demais países ibero-americanos. Assim, a cultura massificada dá unidade à forma de pensar, de agir, de valorar, enfim, integra a todos por meio do consumo de bens materiais e imateriais. É importante registrar que o conceito de indústria cultural foi formulado por Horkheimer e Adorno (1985), tendo como referência o 
desenvolvimento do capitalismo monopolista nos países da Europa e nos Estados Unidos da América na segunda metade da década de 1940.

Considerando que um conceito possui história e movimento, tal como o objeto que ele expressa, seus aspectos imediatos não são suficientes para decifrá-lo. Desde que o termo para designá-la foi cunhado, a indústria cultural, como objeto, sofreu grandes mudanças, todavia sempre mantendo estreita relação com a sociedade de sua época. Se, na atualidade, a tecnologia permite a circulação de informações no tempo real dos acontecimentos - o que não significa a compreensão dos fatores que os perpassam -, o fato de a arte como mercadoria e a indústria cultural como sistema atingir a todos sem distinção não significa que todos distinguem seu fetiche. Análises teóricas são indispensáveis e estas não são isentas de juízos de valor e de aspectos políticos. Nesse sentido, pesquisas que se dedicam à análise crítica sobre a relação entre indústria cultural, sociedade e formação heterônoma são fundamentais para podermos pensar a sociedade para a autonomia.

Em relação a estudos nessa área, o Brasil conta com grupos de pesquisa que há mais de 20 anos desenvolvem trabalhos teóricos e empíricos voltados aos fenômenos sobre os quais os primeiros representantes da Teoria Crítica da Sociedade se debruçaram, bem como tomando esse referencial teórico para iluminar fenômenos como os pertencentes ao campo da educação. Desenvolvem estudos acerca das contradições da cultura e da educação e exploram seu potencial formativo. Dentre esses grupos, podemos citar como exemplo o "Grupo de Pesquisa Teoria Crítica e Educação", criado em 1991, com representantes da Universidade Federal de São Carlos e da Universidade Estadual Paulista - Campus de Araraquara; o "Grupo de Pesquisa Teoria Crítica, Formação e Cultura", com participantes da Universidade de São Paulo e da Pontifícia Universidade Católica de São Paulo; o "Grupo de Pesquisa Nexos: Teoria Crítica e Pesquisa Interdisciplinar Nordeste", formado por pesquisadores de várias instituições de ensino superior. Há inúmeros pesquisadores na Alemanha e também em outros países da Europa e de outros continentes que continuam a tradição dos primeiros pesquisadores da Escola de Frankfurt. Só para mencionar alguns deles, a Alemanha tem Christoph Türcke (Universidade de Leipzig), Andreas Gruschka (Universidade de Frankfurt), Detlev Claussen (Universidade de Hannover), Alex Demirovič (Technische Universität Berlim); José Antonio Zamora (CSIC/Madrid) e Mateu Cabot (Universitat de les Illes Balears) são dois pesquisadores que representam a Espanha.

Esses grupos e pesquisadores, regularmente, realizam seminários e projetos de pesquisas, de modo a promoverem a visibilidade internacional das discussões relacionadas aos fundamentos da Teoria Crítica de Sociedade e, assim, traduzem as experiências e conhecimentos que cada país conquistou. Nossa intenção é adensar o debate e atuar científica e politicamente para que o potencial da Teoria Crítica da Sociedade se realize. 
Neste texto visamos refletir sobre a indústria cultural e a semiformação que, sendo a forma de socialização predominante, tanto atinge países que já alcançaram maior desenvolvimento cultural e tecnológico quanto aqueles em estágios menos desenvolvidos. Independentemente do grau de desenvolvimento econômico e cultural do país, a todos estão disponíveis as mercadorias que, pela formação semelhante de seus cidadãos, mantêm a desigualdade entre eles. Em que medida a Teoria Crítica da Sociedade pode contribuir para que sejam pensados novos direcionamentos para formação? Tais questões advêm de um fato que não pode ser descartado: a sociedade do capitalismo tardio, regida pela indústria cultural, vem sendo questionada e, consequentemente, também a educação e a formação dos indivíduos têm sido criticadas. Esses questionamentos e críticas são feitos mesmo por aqueles que se posicionam favoravelmente à ordem estabelecida, a exemplo dos grupos reacionários que se opõem à democracia e atuam regressivamente para restabelecer o autoritarismo, como, guardadas suas especificidades, tem acontecido em países como o Brasil, a Hungria e a Polônia.

Aqui são necessárias duas ponderações. A primeira diz respeito ao sistema democrático e aos ataques que ele vem sofrendo, quer seja no Brasil, quer seja em outros países. Vivemos uma situação histórica cujas tendências e grupos sociais, no Brasil e no mundo, têm sistematicamente colocado em risco a democracia e os direitos alcançados, por exemplo, com a Declaração Universal dos Direitos Humanos; apesar de formais, a democracia e os direitos conquistados não são insignificantes perante as barbáries já praticadas em diferentes épocas e países. Aqui não é o espaço para enumerar os eventos que constituem as manifestações objetivas de tais tendências e os grupos que as sustentam. Ainda assim, não se pode deixar de mencionar seus efeitos na educação: está em curso um projeto de intervenção nos estabelecimentos de ensino (da educação infantil à superior), capitaneados por segmentos sociais antidemocráticos e avessos à diversidade de ideias, ao debate de propostas e ao confronto de posições, enfim, contrários àquilo que enriquece a experiência humana e fortalece o indivíduo. Essa tentativa de intervir na educação avilta um dos princípios fundantes do regime republicano, qual seja, a liberdade que cada cidadão deve gozar para expressar seus interesses e realizar suas potencialidades.

Em outros termos, no campo educacional está em perigo a possibilidade de os professores de todos os níveis e modalidades de ensino exercerem seu protagonismo no que diz respeito à promoção de valores como justiça, diversidade, pluralidade, igualdade, ética e solidariedade, necessários para alcançarmos um país justo, social e culturalmente rico e desenvolvido. Ora, esse tipo de controle (e de repressão) sobre o trabalho pedagógico constitui atentado ao que as constituições dos países democráticos asseguram aos educadores - liberdade de cátedra e de ensino - e aos estudantes - direito de aprender e ter acesso ao conhecimento, às formas de pensamento, à 
arte e a cultura em geral. Tal situação não é uma ameaça somente à educação. Está em jogo a garantia dos direitos consolidados ao longo da história, principalmente pela ação dos grupos sociais e das pessoas que sofreram, e ainda sofrem, a opressão, resultado das desigualdades que caracterizam nossa sociedade regida pelo sistema capitalista, portanto regida pelas relações de poder e de dominação de uns sobre os outros.

A segunda ponderação se refere à persistência de tendências verificadas nos regimes fascistas e autoritários no interior da democracia (liberal e burguesa). Em função de as pessoas permanecerem em um estado constante de tensão e de frustação, uma vez que todos devemos nos preocupar prioritariamente com a autoconservação, verifica-se uma situação em que os líderes que conseguem canalizar o seu descontentamento oferecem explicações aparentemente racionais para o que é produto da irracionalidade que caracteriza a ordem social (ameaça contínua e permanente, guerra, destruição, interesses do capital como obstáculos à emancipação humana, etc.). Mobilizamse nos indivíduos "os processos irracionais, inconscientes e regressivos” (ADORNO, 2015, p. 184), o que lhes é facilitado justamente pelo seu estado mental e pela prevalência da semiformação que produz essa mentalidade atrofiada e ilógica do ponto de vista da humanidade. De outra parte, não podemos nos esquecer que a adesão à irracionalidade é conquistada por meio da difusão de ideias que articulam certo tipo de crítica à sociedade e impulsos instintivos reprimidos (por exemplo, a noção de que os "poderosos", convertidos em inimigos, conspiram contra as liberdades individuais ou valores que mantêm a coesão social). Além disso, há um vínculo da propaganda de tipo fascista com a propaganda em geral: ambas só alcançam êxito porque exploram a padronização da linguagem (destituída de sentido e de conteúdo real), da informação que diz acerca de tudo sem que nada seja explicado, e lançam mão do pensamento estereotipado.

A educação e a formação contemporâneas, ao priorizarem aspectos que se assentam na racionalidade instrumental ${ }^{4}$, contribuem para a implementação da tendência presente no projeto do Esclarecimento que, segundo os frankfurtianos, tem promovido a regressão da humanidade à barbárie. Assim, delineamos alguns aspectos que caracterizam a educação e a formação nas sociedades modernas, sem nos limitar especificamente aos países ibero-americanos, lembrando,

${ }^{4}$ Sobre a noção de racionalidade instrumental, consultar HORKHEIMER, M. Meios e fins. In: HORKHEIMER, M. Eclipse da razão. São Paulo: Centauro, 2000, p. 11-64. Nesse ensaio, o autor investiga o processo histórico de transformação da razão: “em sua origem, a constituição política foi ideada como uma expressão de princípios concretos fundados na razão objetiva; as ideias de justiça, igualdade, felicidade, democracia, propriedade, todas se proclamavam corresponder à razão, emanar da razão. Posteriormente, o conteúdo da razão foi arbitrariamente reduzido a ser simplesmente uma parte deste conteúdo, em sua extensão, e apenas a um dos seus princípios, na sua composição; o particular tomou o lugar do universal. [...] Tendo cedido em sua autonomia, a razão tornou-se um instrumento. [...] Seu valor operacional, seu papel no domínio dos homens e da natureza tornou-se o único critério para avaliá-la. [...] É como se o próprio pensamento tivesse se reduzido ao nível do processo industrial, submetido a um programa estrito, em suma, tivesse se tornado uma parte e uma parcela da produção" (HORKHEIMER, 2000, p. 29-30). 
porém, que a indústria cultural a todos integra, criando-lhes a falsa ideia de igualdade e de inclusão, quer dizer, a integração se apresenta como mecanismo da exclusão.

Como já mencionado, nosso intento é refletir sobre a indústria cultural e a semiformação (Halbbildung), amparando-nos em teóricos e conceitos da Teoria Crítica de Sociedade que podem elucidar impactos da indústria cultural no campo educacional. Nossa reflexão toma escritos de M. Horkheimer, T. W. Adorno e H. Marcuse, pensadores da primeira geração da Escola de Frankfurt, cuja exposição organizamos da seguinte forma: primeiramente, lançamos luz aos conceitos de indústria cultural e de semiformação, uma vez que a educação e a formação são analisadas com base na interseção entre eles. A reflexão se encaminha para a compreensão da realidade atual, tomando a Teoria Crítica de Sociedade como elemento de esclarecimento acerca da contradição presente na ordem social: a mesma humanidade que caminha para o esclarecimento e para o domínio completo e total da natureza continua reiteradamente produzindo a barbárie.

\section{Indústria cultural e semiformação}

A ideia de que o mundo quer ser enganado tornou-se mais verdadeira do que, sem dúvida, jamais pretendeu ser. Não somente os homens caem no logro, como se diz, desde que isso lhes dê uma satisfação por mais fugaz que seja, como também desejam essa impostura que eles próprios entreveem (ADORNO, 1986, p. 96).

Adorno (1986) denuncia a "chegada" da indústria cultural ${ }^{5}$ quando, em uma das cartas destinadas a Horkheimer, o autor menciona sua expressão sinônima da dialética entre a cultura e a barbárie. Sob a égide de um aparente potencial de igualdade entre os homens (falsa identidade do universal e do particular), a sociedade do capitalismo tardio (século XX e XXI) se depara com novos contornos sociais e econômicos que, de forma ampla, desempenham um papel crucial na dominação sobre os homens pela inovação da técnica e pelo processo de produção de mercadorias, inclusive os bens culturais (ADORNO; HORKHEIMER, 1985).

O fascínio pelas novas possibilidades técnicas de comunicação e de atuação no mundo potencializa a ilusão de que a subjetividade plenamente desenvolvida e autônoma foi estabelecida. Isso condiciona e determina o indivíduo: a formação deveria promover as habilidades de conquista desse mundo, o que impõe a todos a busca por desempenhos (econômicos) eficientes (MARCUSE, 1999). Trata-se de ilusão justamente porque a eficiência depende da integração total na ordem e a consciência torna-se, desse modo, conformista (ADORNO, 1986). Portanto, sob a aparência da liberdade de escolha, do conforto e da segurança que a adesão proporciona ao indivíduo, acontece

${ }^{5}$ O termo indústria cultural foi aparece em 1947, com a publicação de Indústria Cultural: o esclarecimento como mistificação das massas, estudo que compõe a obra Dialética do Esclarecimento, de Adorno e Horkheimer (1985). 
exatamente o contrário. Assim, a pressão econômica, que continua estimulando a luta pela autoconservação, leva à semiformação socializada e, por que não dizer, à educação e à vida danificadas.

Soma-se a essa situação a aparência de que a indústria cultural democraticamente promove o acesso de todos os indivíduos aos bens culturais, independentemente da origem social, o que, por sua vez, estimula ainda mais o consumo, mas somente daquilo que confirma o status quo. Em resumo, a ideologia da indústria cultural opera os seguintes termos: sempre é transmitida uma ordem que deve ser aceita por todos, mas tal ordem não pode ser (e nunca é) confrontada com os reais interesses dos seres humanos (ADORNO, 1986); funciona fornecendo compensações de modo que os indivíduos aceitem que nada deve ser feito porque nada pode ser mudado, afinal aquilo que poderiam ser como seres humanos foi reduzido ao que já são. Adorno (1986, p. 93) afirma:

O consumidor não é rei, como a indústria cultural gostaria de fazer crer, ele não é sujeito dessa indústria, mas seu objeto. O termo mass media, que se introduziu para designar a indústria cultural, desvia, desde logo, a ênfase para aquilo que é inofensivo. Não se trata nem das massas em primeiro lugar, nem das técnicas de comunicação como tais, mas do espírito que lhes é insuflado, a saber, a voz de seu senhor. A indústria cultural abusa da consideração em relação às massas para reiterar, firmar e reforçar a mentalidade destas, que ela toma como dada a priori e imutável. É excluído tudo pelo que essa atitude poderia ser transformada. As massas não são a medida, mas a ideologia da indústria cultural, ainda que esta última não possa existir sem a elas se adaptar.

No cenário da indústria cultural, há a propagação sem medida da fetichização da técnica e da reificação das consciências. O fetiche da mercadoria, conceito cunhado por Karl Marx na sua obra $O$ Capital, na segunda metade do século XIX, advém do fato de que no seu caráter de coisa ela esconde as relações sociais e a exploração do trabalhador pelo capital. Além do valor de uso, existente em qualquer produto, há o valor de troca. $\mathrm{O}$ primeiro diz respeito à utilidade ou à propriedade material que um produto possui para o processo de satisfação das necessidades humanas. Já o valor de troca, por sua vez, refere-se à necessidade de o capital produzir equivalência entre as mercadorias, inclusive à força de trabalho como mercadoria, pois esse mecanismo, que abstrai o valor de uso e as reais necessidades humanas, permite a acumulação e a reprodução do capital. Em outros termos, na mercadoria estão ocultas a dominação social e a exploração econômica dos não proprietários dos meios de produção, formas de satisfação da necessidade do capital: o lucro.

O fetiche da mercadoria cria a ilusão de que o consumo de produtos, quer sejam materiais, quer sejam culturais, quer sejam serviços, atende às necessidades humanas, além de tornar supérfluo o necessário e vice-versa (MARX, 2006). A percepção do indivíduo, nesse sentido, fica presa à 
aparência da mercadoria e à falsa identidade entre o universal e o particular (ADORNO; HORKHEIMER, 1985), a partir do que, de certo modo, estabelece frequentemente relações imediatas entre as manifestações isoladas de um fenômeno e a totalidade social e econômica sem desconfiar que entre uma e outra há uma variedade de mediações possíveis e necessárias. A manipulação se realiza pela associação de forma direta entre a posse de uma mercadoria, a satisfação momentânea e a felicidade.

As massas, afirmei, são manipuladas por força de seus próprios interesses. Por isso, os fenômenos manipulativos falam sobre a língua de interesses reais, ainda que como língua estrangeira de interesses alienados e desfigurados, portanto, irreconhecíveis. A objetividade da felicidade e do sofrimento fundamenta também a da manipulação (HAUG, 1997, p. 14).

Este mecanismo do fetiche da mercadoria está presente na indústria cultural. Para Adorno e Horkheimer (1985, p. 113), isso confere à cultura como mercadoria "um ar de semelhança"; os produtos se entrelaçam em um sistema. Não é de menor importância a tendência aos standards: produções culturais e indivíduos são submetidos a leis da equivalência que enquadram a criatividade, a imaginação, a percepção e a experiência nos moldes da economia política, afetando os sentidos em igual medida tanto de quem produz os bens culturais como daqueles que os recebem. Trata-se de uma situação que potencializa a racionalidade da própria dominação, a qual possui o "caráter compulsivo da sociedade alienada de si mesma" (ADORNO; HORKHEIMER, 1985, p. 114); o indivíduo que se diferencie desse formato comum e único ou que nele se destaque, justamente por se adaptar, é logo descoberto pelos "caçadores de talento". Isso é um modo de conter a reflexão crítica e manter a ordem estabelecida, elevando à condição de popstar a pessoa que participa desse fenômeno, a exemplo do recente status alcançado por blogueiros, youtubers e os chamados influenciadores digitais. ${ }^{6}$

Os mesmos autores afirmam que "o esquematismo do procedimento mostra-se no fato de que os produtos mecanicamente diferenciados acabam por se revelar sempre como a mesma coisa"; isso significa dizer que somente artificial e aparentemente os indivíduos fazem opções, pois prevalece aquilo que lhes é imposto. No entanto, cada um tem a falsa ideia que age de acordo com suas próprias escolhas, ou seja, o indivíduo que está na base da sociedade burguesa, cuja liberdade foi a sua bandeira de luta, encontra-se paralisado, controlado, porém crente que possui liberdade de

${ }^{6}$ As redes sociais são estruturas formadas, principalmente no âmbito da internet, por pessoas e organizações que se conectam mediante interesses ou valores comuns. As novas celebridades do universo digital são pessoas "comuns" que possuem um número elevado de seguidores e produzem variados tipos de conteúdos (moda, saúde, política, educação etc.). Muitas delas são contratadas por empresas para a divulgação e exposição de produtos e marcas aos seus seguidores. 
expressão, de pensamento, quando, a um só tempo, torna-se consumidor de desejos, de gostos e de mercadorias. Essa é a forma com que se promove a própria indústria cultural, uma vez que nada aparece como manipulação dos comportamentos, da sensibilidade e da consciência. Nesse sentido, “para o consumidor, não há mais nada a classificar que não tenha sido antecipado no esquematismo da produção" (ADORNO; HORKHEIMER, 1985, p. 116-17).

Ao mesmo tempo, como assinala Marcuse (1997), na própria cultura sobrevive a dimensão propícia para possibilidade de humanidade - uma vida livre, digna e feliz. Observa-se, portanto, no mesmo movimento no qual o progresso se associa à destruição e à cultura como manipulação e “mistificação das massas”, há a dominação e a persistência histórica da promessa de liberdade e de felicidade. Nesse movimento, prevalece tanto o caráter afirmativo da cultura - a razão definida como instrumento de coação que justifica um estado de exploração social -; como a indicação de que junto a essa tendência há aquela que denuncia a realidade opressiva e vislumbra a possibilidade de uma "ordem existencial" superior, cuja realização impõe a transformação desse "mundo em um novo modo de ser" (MARCUSE, 1972, p. 154). Para isso ser possível, a relação entre razão e sensualidade (sentidos) há de se fazer em termos que não a oposição entre elas. $\mathrm{O}$ autor se refere ao modo como a razão foi reduzida à vida interior dos indivíduos, enquanto a ordem social impunha restrições objetivas, ao mesmo tempo em que aponta a contradição contida nesse processo:

A liberdade da alma foi utilizada para desculpar miséria, martírio e servidão. Ela serviu para submeter ideologicamente a existência à economia do capitalismo. Porém, apreendida corretamente, a liberdade da alma não aponta para a participação do homem num além eterno, onde por fim tudo se resolve quando o indivíduo já não usufrui de nada. Ao contrário, ela pressupõe aquela verdade superior segundo a qual nesse mundo é possível uma forma de existência social em que a economia não decide acerca de toda a vida dos indivíduos. O homem não vive apenas de pão: uma verdade como essa não se esgota pela falsa interpretação de que o alimento espiritual é um substituto suficiente para a falta de pão (MARCUSE, 1997, p. 108).

Seja como for, a reprodução da cultura de massa corrobora para o decréscimo das formas de se pensar o mundo, ou seja, limita a consciência e se alia ao desenvolvimento da razão instrumental. Nesse sentido, impede-se a formação, o que pode ser observado na aversão àqueles que manifestam capacidade crítica e na aversão à experiência com o não idêntico. A vida em geral e as escolhas estão subsumidas e integradas aos ditames da lógica das trocas equivalentes e da cultura estandardizada, restando aos indivíduos a distração e o entretenimento como forma de compensação àquilo que é impedido de ser realizado. Aliás, eles próprios já não anseiam por libertação, pois lhes importa a integração total - condição para a autoconservação. Sobre esse aspecto, Zuin (1999) afirma que a capacidade de avaliar algo como bom ou ruim não pertence ao indivíduo; é apropriada 
pela sociedade administrada. Essa forma de expropriação da subjetividade, além de aprimorar as formas de controle social e de dominação, serve aos propósitos da desumanização. Essa questão pode melhor ser elucidada como as reflexões de Türcke (2010, p. 32), para quem

[...] a teoria considera a propaganda prontamente como aquilo que resultou da restrição ao comercial de produtos, entretenimento, não questionando o que sob esse rótulo funciona como campo programático, sem pensar por um instante nas nuanças econômicas presentes na expressão 'ser entretido', ou na origem daquilo que deve entreter, no jogo, no espetáculo, festival ou ritual, ou sem levantar a menor dúvida a respeito da autonomia do sistema dos meios de comunicação de massa.

Adorno e Horkheimer (1985, p. 151), anteriormente a Türcke, já haviam afirmado que “a cultura é uma mercadoria paradoxal. Ela está tão completamente submetida à lei da troca que não é mais trocada. Ela se confunde tão cegamente com o uso que não se pode mais usá-la. É por isso que ela se funde com a publicidade". Aqui, encontramos mais um aspecto que produz a rigidez do pensamento que se fecha em si mesmo, submetido aos interesses do capital em conciliação com a reprodução da barbárie.

Nesse ponto é possível ressaltar a associação entre a indústria cultural e a semiformação que, entre outros aspectos, condiz com a aversão à experiência do não idêntico. No lugar da experiência autêntica, a indústria cultural preenche a consciência com seus conteúdos ideológicos e, principalmente, com os elementos da tendência geral da sociedade (padronização, lógica da troca de equivalentes, especialização decorrente da divisão social do trabalho sob o capitalismo, abstração do valor de uso etc.) (ADORNO; HORKHEIMER, 1985). Tal situação elimina a diversidade e o outro, enfim, elimina a experiência dos indivíduos com o não idêntico da cultura, ainda que isso aconteça de modo dissimulado, pois a indústria cultural se sustenta na publicidade de que todos, independentemente das diferenças que apresentam, podem usufruir de suas mercadorias. A cultura e seus objetos, purgados de sua concretude real e submetidos à estereotipia do pensamento e ao comportamento repetitivo e automático, desligado da realidade, não é mais acessível à experiência dos indivíduos (ADORNO, 1996), tornando-os, inclusive, avessos a ela.

O desafio a ser enfrentado pela crítica é o de pensar sobre os novos aspectos estabelecidos pelo desenvolvimento da indústria cultural, principalmente no que tange à formação. Ainda parece válida a assertiva para descrever o processo civilizatório: em vez de "entrar em um estado verdadeiramente humano, está se afundando em uma nova espécie de barbárie" (ADORNO; HORKHEIMER, 1985, p. 11). Nesse sentido, a formação (Bildung) e a educação têm se conformado aos marcos do capitalismo tardio e da indústria cultural, em articulação com a 
racionalidade tecnológica (MARCUSE, 1999) e a semiformação (Halbbildung), que promovem, predominantemente, a adaptação e a coisificação do pensamento. A desumanização conduzida pelo sistema capitalista e pela indústria cultural é exatamente isso - "o homem de espírito é um espécime em extinção; em seu lugar viceja o homem pretensamente realista" (PUCCI, 2009, p. 70, grifo no original). Este mesmo autor, ancorado em ideias de Adorno, acrescenta:

As imagens e formas culturais que a caracterizavam [a formação] foram substituídas pelas imagens das artistas de cinema, e pelas canções de sucesso, que, com sua beleza produzida, suas letras e seus títulos padronizados, irradiavam um brilho calculado. As boas maneiras à mesa e no tratamento com o outro, a perda de tempo com a escolha de um presente para a pessoa amada, a lenta construção de experiências duradouras, a precisão escrupulosa na maneira de se expressar, a presença repentina do ato de aprender de cor e do testemunho da memória das coisas, são progressiva e definitivamente trocadas pelo tratamento direto, pela funcionalidade, pela precisão, pela rapidez, pela memória das máquinas (PUCCI, 2009, p. 70).

Enfim, se a Teoria Crítica da Sociedade apresenta elementos para se opor à força avassaladora da objetividade que impõe aos indivíduos a adesão voluntária aos seus ditames, isso depende de uma prática científica e política que investigue as raízes da irracionalidade presente na sociedade e de sua produtividade destruidora do livre desenvolvimento das necessidades e faculdades humanas (MARCUSE, 1969). De um lado, temos o colapso da formação cultural, que se faz observar por toda a parte e que não se encerra nas insuficiências do sistema educacional, aprisionando os indivíduos nas malhas da ilusória socialização (ADORNO, 1996); de outro lado, temos o crescente avanço das forças produtivas e o desenvolvimento da racionalidade tecnológica, que impõe cada vez mais a dominação da sociedade sobre o indivíduo (MARCUSE, 1969).

Sendo este o diagnóstico, Marcuse assim (1969) define o objetivo da Teoria Crítica da Sociedade: investigar e examinar as possibilidades históricas utilizadas, não utilizadas e mal utilizadas para aprimorar a condição humana. Portanto, trata-se de uma ação teórica e prática que envolve o que entende por objetividade histórica, considerando:

1) o julgamento de que a vida humana [...] pode ser ou deve ser tornada digna de se viver. Este julgamento alicerça todo o esforço intelectual; é apriorístico para a teoria social, e sua rejeição [...] rejeita a própria teoria;

2) o julgamento de que, em determinada sociedade, existem possibilidades específicas de melhorar a vida humana e os modos e meios específicos de realizar essas possibilidades. [...] A sociedade estabelecida dispõe de uma quantidade e de uma qualidade determináveis de recursos utilizados para o máximo desenvolvimento de recursos intelectuais e materiais. Como podem ser esses recursos utilizados para o máximo desenvolvimento e satisfação das necessidades e faculdades individuais com o mínimo de labuta e miséria? Teoria social é teoria histórica, e história é a esfera da possibilidade na esfera da necessidade (MARCUSE, 1969, p. 14-15). 
Para o autor, o aprimoramento da condição humana somente poderá ser realizado quando a tendência ao irracional, presente no seio da própria civilização, puder ser combatida objetivamente - e não somente no plano abstrato da teoria, ainda que esta exerça um papel político indispensável. Significa isso afirmar que é fundamental abolir as relações sociais de dominação (das quais o capitalismo se nutre ao mesmo tempo que as desenvolve), além de realizar a pacificação da luta pela existência (reorientando o curso da história para que o progresso não possa mais se alimentar da agressão e da destruição).

Desde os anos 1930, quando Horkheimer (1991) escreveu o basilar ensaio Teoria tradicional e teoria crítica, continua sendo papel importante o de examinar os motivos que produziram e desenvolveram a racionalidade instrumental, a semiformação, a indústria cultural, o entrelaçamento de esclarecimento e barbárie, enfim, as condições objetivas e subjetivas que geram o fascismo, o ódio, a violência e o preconceito no seio dos regimes democráticos. Nesse sentido, mais do que nunca é necessário recorrer às contribuições dos autores da Escola de Frankfurt.

\section{Teoria Crítica da Sociedade como possível resistência ao instituído no contexto ibero- americano: Considerações finais}

Partimos do pressuposto de que se no momento social vigente opera a hegemonia da razão instrumental (razão subjetiva) sobre a razão emancipatória (razão objetiva) a serviço da propagação da dominação e das injustiças sociais, isso não significa que tenha de ser sempre dessa forma.

Apesar de não termos alcançado a vida digna para todos, a democracia já conquistada não é pouco, todavia, o próprio esquecimento do passado tem nos levado a olvidarmos não apenas da barbárie, mas do próprio direito à não regressão. Em nome da civilização e do acesso aos bens de consumo, colocamo-nos como merecedores de mercadorias que nos identificam e em vez de nos unirmos em favor da humanidade, a união se faz em favor da reprodução do capital, mesmo que isso possa significar a destruição da própria humanidade.

Como argumentado no início deste ensaio, os objetos e conceitos têm movimento e história, cuja compreensão se faz necessária para que o essencial possa ser revelado. Nesses termos, não é possível falar em países ibero-americanos apartados do capitalismo avançado e dos mecanismos utilizados para a sua reprodução, sendo a indústria cultural um deles. Na atualidade, esta última tem servido, inclusive, para o ataque à democracia e à educação em todas as partes do mundo.

O fato de histórica e politicamente a Organização dos Estados Ibero-americanos para a Educação, a Ciência e a Cultura (OIE) ter sido constituída há 90 anos não significa que os países que a compõem sejam protegidos dos mecanismos utilizados pelo capitalismo avançado para a sua 
reprodução, já que os princípios que garantem esta reprodução perpassam os fins e objetivos dessa Organização.

Ao destacarmos, por exemplo, o segundo objetivo da OIE, conforme seu regulamento orgânico em vigência desde 1985, podemos observar que a educação, a cultura e o sujeito que é formado são definidos como alternativa para que a sociedade democrática e do direito se efetive. Assim está redigido o objetivo:

2. Fomentar o desenvolvimento da educação e da cultura como alternativa válida e viável para a construção da paz, mediante a preparação do ser humano para o exercício responsável da liberdade, da solidariedade e da defesa dos direitos humanos, assim como apoiar as mudanças que permitam uma sociedade mais justa para a América Latina (ORGANIZAÇÃ̃O DOS ESTADOS IBEROAMERICANOS).

Portanto, o que se observa é a prevalência de uma concepção que deposita as esperanças na educação e na cultura (fatores pertencentes à superestrutura da sociedade) no que se refere às transformações que redundariam na superação da desigualdade e da exploração. E isso em razão da estrutura social e da base econômica não serem contestadas, ou porque se avalia que é no âmbito do capitalismo que a liberdade e a justiça se realizarão, ou porque há um sentimento de impotência frente ao poder da realidade objetiva. Ora, somente por meio de um processo de emancipação social, produto de ação política organizada, será possível a transformação social.

A Teoria Crítica da Sociedade como possibilidade de resistência ao instituído requer algumas ponderações, com as quais finalizamos nossa reflexão: como possibilitar que este objetivo se cumpra se a formação que se desenvolve na escola e fora dela é para a adaptação à sociedade na qual a promessa de liberdade, de fraternidade, de igualdade e de justiça não se cumpriu? Como é possível uma sociedade justa se ela é amparada pela troca cuja justiça é o lucro? Se a sociedade não é justa, como pode a escola formar para o contrário disso? Parece que uma possibilidade de resistência é pensar em uma escola que possa se distanciar o suficiente da sociedade para, então, compreender o seu funcionamento e seu movimento, para a tomada de consciência de que somos seduzidos cotidianamente pelas mercadorias anunciadas por meio da indústria cultural. Resta-nos lutar não pela possibilidade de consumo, mas contra a sociedade do consumo e pensar em uma escola que proporcione o acesso ao conhecimento sistematizado - o fracasso escolar é mais uma das formas de injustiça.

Por fim, os autores da Teoria Crítica da Sociedade nos autorizam a afirmação de que um dos fundamentos da prática educativa é a democracia. A defesa de tal postulado não está assentada em mera idealização ou crença abstrata no poder da educação, mas em um posicionamento político. 
Para Adorno (1995, p. 141), educação é “a produção de uma consciência verdadeira". O autor continua:

Isto seria inclusive da maior importância política; sua ideia, se é permitido dizer assim, e uma exigência política. Isto é: uma democracia com o dever de não apenas funcionar, mas operar conforme seu conceito, demanda pessoas emancipadas. Uma democracia efetiva só pode ser imaginada enquanto uma sociedade de quem é emancipado. Numa democracia, quem defende ideais contrários a emancipação, e, portanto, contrários à decisão consciente independente de cada pessoa em particular, é um antidemocrata, até mesmo se as ideias que correspondem a seus desígnios são difundidas no plano formal da democracia. As tendências de apresentação de ideais exteriores que não se originam a partir da própria consciência emancipada, ou melhor, que se legitimam frente a essa consciência, permanecem sendo coletivistas-reacionárias. Elas apontam para uma esfera a que deveríamos nos opor não só exteriormente pela política, mas também em outros planos muito mais profundos (ADORNO, 1995, p. 141-42).

Em um momento extremamente grave e dramático da história do Brasil e de muitos outros países ibero-americanos, com a democracia e a educação sendo atacadas por aqueles que insistem em permanecermos nações servis e subservientes e com a maior parte da população submissa aos padrões que perpetuam a desigualdade social, étnica-racial, regional e de gênero, fazendo uso de expedientes como a manipulação dos fatos, a ameaça, a repressão e a violência, enfim, nessa situação são muito oportunas investigações orientadas pela Teoria Crítica da Sociedade, com análises e desdobramentos consequentes, que evidenciem o que está envolvido na produção e reprodução da violência e do preconceito, inclusive na escola - sabemos que estes não são fenômenos restritos ao campo da educação e que as sociedades ibero-americanos têm como uma de suas marcas históricas a violência praticada contra grupos e pessoas que se contrapõem à ordem social, muitas vezes porque simplesmente sua existência põe em xeque os padrões e normas sociais.

Assim, podemos lançar luz sobre a irracionalidade contida nas relações sociais que têm lugar na escola e em outros espaços e indicar caminhos para o combate às situações que vitimam um contingente significativo de pessoas tão somente porque elas existem de determinada maneira; e existindo de formas distintas das consideradas em conformidade com o padrão dominante mostram toda a riqueza e diversidade humana que possuímos.

No entanto, os que praticam a violência e a dominação são pessoas que (até inconscientemente) ou não admitem abrir mão da posição de poder que detêm ou são avessas às diferenças e à diversidade humanas. Por essas razões, é fundamental atrelar democracia e educação, até porque: 
[...] a democracia não se estabeleceu a ponto de constar da experiência das pessoas como se fosse um assunto próprio delas, de modo que elas compreendessem a si mesmas como sendo sujeitos dos processos políticos. Ela é apreendida como sendo um sistema entre outros, como se num cardápio escolhêssemos entre comunismo, democracia, fascismo ou monarquia; ela não é apreendida como identificando-se ao próprio povo, como expressão de sua emancipação (ADORNO, 1995, p. 35).

Os educadores talvez pudessem, como postula Adorno (1995), levar a sério a educação política orientada sociologicamente no sentido de incorporar os conteúdos relacionados às disputas por interesses e às relações de poder (que definem as correlações de forças políticas entre grupos e classes socais) e, também, utilizar os conhecimentos psicanalíticos e da psicologia social, justamente para fazer frente àquilo que está subjacente à constituição das subjetividades, uma vez que indivíduos agressivos, intolerantes, manipuladores e violentos continuam sendo formados, inclusive nas escolas. Desse modo, algo quiçá pode ser feito na contraposição à ordem social capitalista que produz as condições objetivas e subjetivas de sua reprodução e manutenção.

\section{REFERÊNCIAS}

ADORNO, T. W.; HORKHEIMER, M. Dialética do esclarecimento: fragmentos filosóficos. Rio de Janeiro: Jorge Zahar, 1985.

ADORNO, T. W. A Indústria Cultural. In: COHN, G. (org). Theodor W. Adorno. São Paulo: Ática, 1986, p. 92-99. (Coleção Grandes Cientistas Sociais)

ADORNO, T. W. Teoria freudiana e o padrão de propaganda fascista. In: ADORNO, T. W. Ensaios sobre psicologia social e psicanálise. São Paulo: Ed. UNESP, 2015, p. 153-189.

ADORNO, T. W. Teoria da semicultura. Educação e sociedade, Campinas, n. 56, ano XVII, dez., p. 388-411, 1996.

ADORNO, T. W. Educação e emancipação. Rio de Janeiro: Paz e Terra, 1995.

HAUG, W. F. Crítica da estética da mercadoria. São Paulo: Unesp, 1997.

HORKHEIMER, M. Meios e fins. In: HORKHEIMER, M. Eclipse da razão. São Paulo: Centauro, 2000, p. 13-64.

HORKHEIMER, M. Teoria tradicional e teoria crítica. In: HORKHEIMER, M.; ADORNO, T. W. Textos escolhidos. São Paulo: Nova Cultural, 1991. p. 31-68. (Col. Os Pensadores).

MARX, K. O capital. Rio de Janeiro: Civilização Brasileira, 2006.

MARCUSE, H. Sobre o caráter afirmativo da cultura. In: MARCUSE, H. Cultura e sociedade. Rio de Janeiro: Paz e Terra, 1997, v. 1, p. 89-136. 
MARCUSE, H. Eros e civilização: uma interpretação filosófica do pensamento de Freud. Rio de Janeiro: Zahar, 1972.

MARCUSE, H. Ideologia da sociedade industrial. Rio de janeiro: Zahar, 1969.

MARCUSE, H. Algumas implicações sociais da tecnologia moderna. In: MARCUSE, H.

Tecnologia, guerra e fascismo. São Paulo: Ed. Unesp, 1999. p. 71-104.

ORGANIZAÇÃO DOS ESTADOS IBERO-AMERICANOS. O que é a OIE? Disponível em: https://oei.org.br/oei. Acesso em: 20. jun. 2019.

PUCCI, B. A escola e a semiformação mediada pelas novas tecnologias. In: PUCCI, B.; ALMEIDA, J. de; LASTÓRIA, L. A. C. N. (Orgs.). Experiência formativa e educação. São Paulo: Nankin, 2009. p. 69-79.

TÜRCKE, C. Sociedade excitada: filosofia da sensação. Campinas: Ed. Unicamp, 2010.

ZUIN, A. A. S. Indústria cultural e educação: o novo canto da sereia. Campinas: Autores Associados, 1999.

\section{Como referenciar este artigo}

OLIVEIRA, Marta Regina Furlan de; GALUCH, Maria Terezinha Bellanda; GIOVINAZZO JÚNIOR, Carlos Antônio. Indústria Cultural e Semiformação: Democracia e Educação sob ataque nos Países Ibero-Americanos à Luz da Teoria Crítica. Revista Ibero-Americana de Estudos em Educação, Araraquara, v. 14, n. esp. 4, p. 1883-1898, dez. 2019. E-ISSN: 1982-5587. DOI: https://doi.org/10.21723/riaee.v14iesp.4.12912

Data de submissão: 25/06/2019

Aprovado em: 28/07/2019

Data de publicação: 01/09/2019 